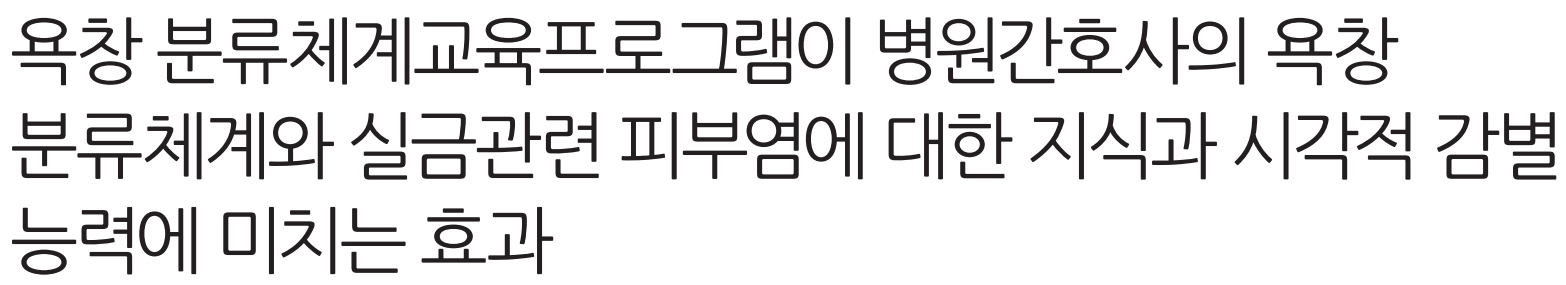

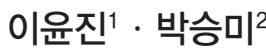

1세브란스병원 간호국, ${ }^{2}$ 호서대학교 간호학과 \& 기초과학연구소

\title{
Effects of Pressure Ulcer Classification System Education Program on Knowledge and Visual Discrimination Ability of Pressure Ulcer Classification and Incontinence-Associated Dermatitis for Hospital Nurses
}

Yun Jin Lee ${ }^{1}$, Seungmi Park ${ }^{2}$

${ }^{1}$ Department of Nursing, Yonsei University Health System, Severance Hospital, Seoul; '2Department of Nursing \& Reserach Institute for Basic Sicences, Hoseo University, Asan, Korea

\begin{abstract}
Purpose: The purpose of this study was to examine the effects of pressure ulcer classification system education on hospital nurses' knowledge and visual discrimination ability of pressure ulcer classification system and incontinence-associated dermatitis. Methods: One group pre- and post-test was used. A convenience sample of 96 nurses participating in pressure ulcer classification system education, were enrolled in single institute. The education program was composed of a 50-minute lecture on pressure ulcer classification system and case-studies. The pressure ulcer classification system and incontinence-associated dermatitis knowledge test and visual discrimination tool, consisting of 21 photographs including clinical information were used. Paired t-test was performed using SPSS/ WIN 18.0. Results: The overall mean difference of pressure ulcer classification system knowledge $(t=4.67, p<.001)$ and visual discrimination ability ( $\mathrm{t}=10.58, p<.001)$ were statistically and significantly increased after pressure ulcer classification system education. Conclusion: Overall understanding of pressure ulcer classification system and incontinence-associated dermatitis after pressure ulcer classification system education was increased, but tended to have lack of visual discrimination ability regarding stage III, suspected deep tissue injury. Differentiated continuing education based on clinical practice is needed to improve knowledge and visual discrimination ability for pressure ulcer classification system, and comparison experiment research is required to evaluate its effects.
\end{abstract}

Key Words: Pressure ulcer; Nurses; Knowledge; Dermatitis

국문주요어: 욕창분류체계, 지식, 피부염, 간호사

\section{서 론}

\section{1. 연구의 필요성}

욕창은 응전력이나 마찰력, 또는 지속적으로 조직에 가해지는
압력으로 인해 발생하는 피부 및 조직의 손상으로(Baumgarten et al., 2006) 욕창 발생 시 재원기간의 연장, 치료와 검사로 인한 불필요 한 의료비 지출의 증가 등의 경제적 손실을 유발하며, 제대로 관리 되지 않을 경우 감염과 같은 합병증이 진행되어, 사망의 위험성도

Corresponding author: Seungmi Park

Department of Nursing, Hoseo University, 79-20 Hoseo-ro, Sechul-ri, Baebang-eup, Asan 336-795, Korea

Tel: +82-41-540-9533 Fax:+82-41-540-9558 E-mail: seungmipark@hoseo.edu

투고일: 2014년 10월 1일 심사의뢰일: 2014년 10월 1일 게재확정일: 2014년 10월 30 일

This is an Open Access article distributed under the terms of the Creative Commons Attribution Non-Commercial License(http://creativecommons.org/licenses/by-nc/3.0) which permits unrestricted non-commercial use, distribution, and reproduction in any medium, provided the original work is properly cited. 
증가시키는 심각한 건강문제이다(Hopkins, Dealey, Bale, Defloor, \& Worboys, 2006). 또한 욕창은 국내외적으로 환자 안전에 관한 문제 로 인식되면서 그 중요성이 점차 강조되고 있다.

욕창 관리는 환자를 돌보는 모든 의료인들의 유기적인 협력을 통 해서 이루어지나, 간호사는 입원 시 환자의 욕창 발생 위험요인과 피부상태를 사정하며, 기본간호업무로서 욕창 발생 위험 환자를 정 기적, 지속적으로 관찰하고 체위변경이나 예방적 피부간호 등의 일 차적 간호업무를 독자적으로 수행하므로 전반적인 욕창 관리에서 간호사는 매우 중추적인 역할을 담당하고 있다(Hopkins et al., 2006). 그러므로 욕창을 예방하고 사정하며, 근거에 기반한 과학적 중재를 제공하는 전반적인 욕창 관리에 있어 간호사의 역량은 매 우 중요하다고 할수 있다(Aydin \& Karadag, 2010).

이와 같이 욕창을 정확하게 사정하고 조기 발견하여 효율적 간 호를 수행하기 위해서는 간호사의 욕창에 대한 정확한 지식 함양 이 무엇보다도 중요하나, 선행연구를 살펴보면 간호사들의 욕창 관 련 지식수준은 높지 않으며(Lee, Kim, \& Lee, 2011; Lee, Park, Kim, Kim, \& Cha, 2013; Lee \& Yang, 2011), 최근 간호현장에서는 실금관련 피부염과 욕창을 혼돈하여 욕창 예방과 치료에 심각한 오류를 일 으키고 있는 실정이다(Hopkins et al., 2006). 실금관련 피부염은 회음 부의 피부가 소변이나 대변에 오랜 시간 오염되어 피부에 염증이 나 타나는 것으로(Gray, Bohacek, Weir, \& Zdanuk, 2007; Gray, 2010), 발생 원인과 기전이 욕창과 다르지만 회음부라는 발생부위가 욕창과 유 사하여 욕창과 구분하는데 어려움이 있을 수 있다. 그러나, 욕창과 실금관련 피부염을 혼동하는 것은 올바르지 못한 예방간호를 제공 하지 못하게 하여 관리의 어려움을 유발할 수 있기 때문에, 간호사 들로 하여금 욕창과 실금관련 피부염을 정확히 구분해 낼 수 있도 록 할 필요가 있다(Beeckman, Schoonhoven, Boucqué, Van Maele, \& Defloor, 2008).

실금관련 피부염과 욕창 간의 구분이 혼란스러울 뿐 아니라, 국 내 간호사들은 새로이 보완된 욕창 분류체계에 따른 6단계 욕창 분 류에도 어려움을 겪는 것으로 나타났다(Lee et al., 2013). 욕창 분류체 계 및 이와 혼동을 일으키는 실금관련 피부염에 대한 간호사의 지 식과 감별능력을 살펴본 최근 연구에 따르면, 간호사들의 욕창 3 단 계 지식 수준이 낮았고, 욕창 사정에서 가장 중요한 시각적 감별 능 력도 낮게 나타났다(Lee et al., 2013). 또한 새롭게 추가된 심부조직손 상 의심단계와 미분류단계에 대한 시각적 감별 능력 또한 매우 낮은 수준을 보이면서, 정확한 욕창 사정에 문제가 있음이 지적되었다.

이 같은 정확한 욕창 분류체계에 대한 진단의 문제점을 해결하 기 위해 국외에서는 웹기반 프로그램과 욕창 관리를 위한 대규모 질 관리 프로그램, 근거에 기반한 교육과 강의와 사진을 이용한 교
육프로그램을 시행하였음을 보고하였으며, 이를 통하여 간호사의 욕창 예방과 관리에 대한 지식이 향상되었다고 하였다, 또한 욕창 분류체계와 실금관련 피부염과의 구별 지식 향상에 긍정적 효과가 있음을 보고하였다(Beeckman et al., 2008; Kim \& Chung, 2013; Sinclair et al., 2004). 이처럼 간호사의 지식 증진을 위해 욕창 예방과 치 료에 대한 계속 교육의 필요성이 제기되고 있지만, 아직까지 국내에 서는 임상 현장에서 이루어지고 있는 새로운 욕창 분류체계에 대 한 교육이나 훈련 후에 간호사의 지식이나 기술의 향상에 대한 연 구는 제한적이다. 특히, 선행연구에서 욕창 분류체계 및 이와 혼동 을 일으키는 실금관련 피부염의 발생 원인에 따른 명확한 구분을 강조한 프로그램이 필요하다.

따라서 본 연구의 목적은 병원간호사를 대상으로 욕창 분류체 계 교육프로그램을 제공하고, 교육 전후의 욕창 분류체계와 실금 관련 피부염에 대한 지식에 대한 이해 정도와 시각적 감별 능력을 평가해보고, 그 차이를 확인하여 추후 욕창 분류체계에 대한 간호 교육 프로그램 개발에 기초자료로 삼고자 시도되었다.

\section{2. 연구의 목적}

본 연구는 병원간호사를 대상으로 욕창 분류체계 교육프로그램 의 적용이 욕창 분류체계와 실금관련 피부염에 대한 지식 정도와 시각적 감별 능력에 미치는 효과를 검정하고자 하여 실시하였다.

\section{3. 연구 가설}

가설 1. 욕창 분류체계 교육프로그램에 참여한 병원간호사의 욕 창 분류체계와 실금관련 피부염에 대한 지식 점수는 교육 전보다 교육 후에 높아질 것이다.

가설 2. 욕창 분류체계 교육프로그램에 참여한 병원간호사의 욕 창 분류체계와 실금관련 피부염에 대한 시각적 감별능력 점수는 교 육 전보다 교육 후에 높아질 것이다.

\section{4. 용어의 정의}

\section{1) 욕창 분류체계}

미국욕창자문위원단(NPUAP, National Pressure Ulcer Advisory Panel)과 유럽욕창자문위원단(EPUAP, European Pressure Ulcer Advisory Panel)에서 피부손상의 심각성에 기초하여 1 단계, 2 단계, 3 단 계, 4단계, 미분류, 심부조직손상 의심의 6단계로 재구성한 분류체 계를 의미한다.

\section{2) 실금관련 피부염 \\ 회음부 또는 항문 주위 피부에 장기간 대소변이 접촉함으로써}


각질층의 짓무름(maceration)과 표피 미란에 의해 피부손상이 동반 되어 있거나 동반되어 있지 않더라도 피부장벽기능의 결함으로 발 생한 피부염을 말한다.

\section{3) 욕창 분류체계 교육 프로그램}

욕창과 실금관련 피부염의 발생기전과 위험요인, 예방적 접근, 욕 창 분류체계로 구성된 이론적 내용과 실제 임상에서의 사례를 중 심으로 50 분간 연구자에 의해 제공된 교육프로그램이다.

\section{5. 연구의 제한점}

본 연구는 연구대상을 편의 추출하여 $\mathrm{S}$ 병원으로 한정하여 시행 하였으며, 대조군이 없는 연구로, 그 결과를 전체 병원간호사에게 적용하기에는 제한이 있다. 또한 욕창 분류체계와 실금관련 피부염 에 대한 지식 정도와 시각적 감별 능력을 묻는 항목만을 가지고 간 호사의 이론적 지식과 실무적용을 평가함에는 무리가 있으며, 실 제 임상에서의 직접적인 시진과 촉진, 관찰을 통한 욕창 분류와 실 금관련 피부염의 감별진단이 아닌 임상정보가 일부 제공된 사진을 가지고 감별능력을 평가하는데 제한이 있어 추가적인 연구가 필요 하다.

\section{연구 방법}

\section{1. 연구 설계}

본 연구는 병원간호사의 욕창 분류체계와 실금관련 피부염의 지 식과 시각적 감별능력의 교육 전과 후의 차이를 확인하기 위한 단 일군 전후 실험연구이다.

\section{2. 연구 대상}

본 연구는 연구자의 편의추출에 의해 서울에 소재하는 일개 상 급종합병원에 근무하는 간호사를 대상으로 하였다. 욕창 사정교육 프로그램에 참여한 S 병원간호사 중 연구의 목적을 이해하고 연구 참여에 동의한 간호사를 대상으로 하였다. 연구 대상자 수는 $\mathrm{G}$ power 3.1 프로그램을 이용하여 산출한 결과 선행연구에 의한 효과 크기를 기준으로 하여(Altun \& Zencirci, 2011), 유의수준 .05, mean of paired differences 3.5, SD of paired differences 7.0, 통계적 검정력 .90 으로 하였을 때 44 명이 필요한 것으로 확인되었다. 본 연구에 참여 한 간호사는 107 명이었으며, 자료가 부실한 11 부를 제외하고 96 명 의 자료를 분석하였다.

\section{3. 연구 도구}

1) 욕창 분류체계와 실금관련 피부염 지식 측정도구

욕창 지식에 대한 $\operatorname{Kim}$ (2003)의 도구와 욕창 분류체계 및 실금관 련 피부염에 대한 문헌을 바탕으로 Lee 등(2013)의 연구에서 개발되 어 타당도와 신뢰도가 확인된 도구로 19 문항으로 구성되었으며, 단 계별 욕창과 실금관련 피부염에 대한 설명을 읽고 문항의 내용이 옳으면 '예', 틀리면 '아니요라고 응답하게 하여, 정답은 1점, 오답은 0 점으로 환산하였다. 점수의 범위는 0-19점이고 점수가 높을수록 지 식 정도가 높음을 의미한다. Lee 등(2013)의 연구에서의 신뢰도는 K-R 20 (Kuder-Richardson Formula 20)=.39였으며, 본 연구에서의 $\mathrm{K}-\mathrm{R} 20=.97$ 이었다.

\section{2) 욕창 분류체계와 실금관련 피부염 시각적 감별능력 측정도구}

욕창 분류체계와 실금관련 피부염 감별을 위해 Lee 등(2011)이 개 발한 도구로 21장의 사진과 함께 의학적 진단, 환자 기동성, 배변상 태, 경관유동식 주입 유무, 상처보유기간 등 환자의 임상적 상태 정 보가 명시되어 있다. 21 장의 사진은 6단계의 욕창 단계별 사진 16장, 창백성 홍반 사진 2장, 실금관련 피부염 사진 3장으로 구성되어 있 으며, 정답은 1 점, 오답은 0 점으로 환산하였고, 점수의 범위는 0-21 점, 점수가 높을수록 시각적 감별 능력 정도가 높음을 의미한다. 개 발 당시의 신뢰도는 Multi-rater kappa $=0.81$ ( $p<.001)$ 이었고, 본 연구 에서의 신뢰도는 K-R $20=.79$ 였다.

\section{4. 자료 수집}

본 연구는 자료수집기관의 허가를 득한 후 실행되었다. 연구 대 상자에게 연구의 목적과 내용을 설명하고 자의에 의한 참여로 연구 가 이루어지며, 응답한 내용은 연구 목적 외의 다른 목적으로 사용 되지 않으며, 개인의 신상에 대한 비밀을 보장하고, 대상자가 원하 면 언제든지 철회할 수 있음을 설명하였다. 연구 참여 의사를 확인 하여 서면 동의를 받은 후 연구를 진행하였다.

본 연구의 자료수집은 2012년 5월부터 12 월까지 시행되었다. 50분 의 욕창 사정 교육내용은 최근 발표된 6단계 욕창 분류단계를 기반 으로 하여 구성하였고, 여기에 욕창과 혼동을 줄 수 있는 실금관련 피부염을 비교하여 다양한 임상 사진과 더불어 사례 중심을 교육 을 실시하였다.

교육 전후 욕창 분류체계와 실금관련피부염 지식에 관한 설문지 를 연구대상자가 읽고 직접 기입하도록 하였으며, 시각적 감별능력 을 측정하기 위한 설문지는 PPT를 이용한 사진자료를 화면을 통한 슬라이드를 각각 본 후작성하도록 하였다. 


\section{5. 자료 분석}

수집된 자료는 SPSS/WIN 18.0 프로그램을 이용하여 전산통계 처 리하였다. 분석방법으로는 연구대상자의 일반적 특성과 욕창 분류 체계와 실금관련 피부염 지식정도와 시각적 감별 능력점수는 평균 과 표준편차로 분석하였으며, 대상자의 교육 전후의 욕창 분류체계 와실금관련 피부염의 지식정도와시각적 감별능력 점수는 paired ttest로 분석하였고, 욕창 분류체계와 실금관련 피부염에 대한 시각 적 감별 능력 영역별 분석은 기술통계를 사용하였다.

Table 1. General Characteristics

\begin{tabular}{|c|c|c|}
\hline Characteristics & & $n(\%)$ or Mean \pm SD \\
\hline \multirow[t]{4}{*}{ Age (year) } & $<30$ & $40(48.8)$ \\
\hline & $30-39$ & $29(35.4)$ \\
\hline & $\geq 40$ & $13(15.8)$ \\
\hline & Mean \pm SD & $30.6 \pm 7.75$ \\
\hline \multirow[t]{2}{*}{ Gender } & Male & $1(1.1)$ \\
\hline & Female & $90(98.9)$ \\
\hline \multirow[t]{3}{*}{ Education } & Diploma & $14(15.1)$ \\
\hline & Bachelor & $67(72.0)$ \\
\hline & $\geq$ Master & $12(12.9)$ \\
\hline \multirow[t]{5}{*}{ Position } & Staff nurse & $64(68.8)$ \\
\hline & Charge nurse & $18(19.4)$ \\
\hline & Unit manager & $8(8.6)$ \\
\hline & Nurse specialist & $2(2.1)$ \\
\hline & The others & $1(1.1)$ \\
\hline \multirow[t]{4}{*}{ Career length (year) } & $<5$ & $38(42.7)$ \\
\hline & $5-9$ & $17(19.1)$ \\
\hline & $\geq 10$ & $34(38.2)$ \\
\hline & Mean \pm SD & $8.3 \pm 4.2$ \\
\hline \multirow[t]{4}{*}{ Unit } & Surgical & $31(34.0)$ \\
\hline & Medical & $26(28.6)$ \\
\hline & Intensive care unit & $20(22.0)$ \\
\hline & Other & $14(15.4)$ \\
\hline \multirow{4}{*}{$\begin{array}{l}\text { Frequency of pressure ulcer } \\
\text { management }\end{array}$} & $<3 /$ month & $45(49.4)$ \\
\hline & 1/week & $15(16.5)$ \\
\hline & 2-4/week & $20(22.0)$ \\
\hline & $\geq 5 /$ week & $11(12.1)$ \\
\hline \multirow{3}{*}{$\begin{array}{l}\text { Participation of pressure ulcer } \\
\text { management or wound } \\
\text { education program }\end{array}$} & None & $27(30.0)$ \\
\hline & $1-2$ & $52(57.8)$ \\
\hline & $\geq 3$ & $11(12.2)$ \\
\hline
\end{tabular}

*The total sample size may not equate to the breakdown because of missing data.

\section{연구 결과}

\section{1. 연구대상자의 일반적 특성}

연구대상자의 일반적 특성을 Table 1에 정리하였다. 대상자의 평 균 연령은 $30.6 \pm 7.75$ 세로, 30 세 미만이 $42.1 \%$ 로 가장 많았고, 여성이 94.7\%였다. 4년제 간호학과 졸업자가 $70.5 \%$ 로 가장 많았으며, 직위는 일반간호사가 $67.4 \%$, 전문간호사는 $2.1 \%$ 를 차지하였다. 대상자의 평 균 임상경력은 8.38..4.2년으로, 5 년 미만이 $40.4 \%$ 를 차지해 가장 많 았으며, 10 년 이상이 $35.8 \%$ 를 차지하였다. 근무 병동은 외과계 $32.6 \%$, 내과계 27.4\%, 중환자실 $21.1 \%$ 로 나타났다. 욕창 환자를 얼마나 자주 접하는지에 대한 질문은 3 회 이하/월'가 $47.4 \%$ 로 가장 많은 수가 답 하였으며, '2-4회 이하/주는 $21.1 \%$, '1회/주가 $15.8 \%$ 라고 답하였다. 욕 창이나 상처관련 교육경험이 1-2회인 경우가 $54.7 \%$ 를 차지하였고, 3 회 이상은 $11.6 \%$ 를 차지하였지만, 교육을 한 번도 받지 않은 대상자 는 $28.4 \%$ 였다.

\section{2. 교육 전 후 지식 및 시각적 감별 능력의 변화}

연구대상자의 욕창 분류체계 및 실금관련 피부염에 대한 이론적 지식과 시각적 감별 능력의 교육 전후 차이를 Table 2에 정리하였다. 지식의 평균 점수는 교육 전이 $12.4 \pm 4.4$ 점, 교육 후 $14.9 \pm 3.3$ 로 상승 하여 통계적으로 유의한 차이가 있었다 $(\mathrm{t}=4.67, p<.001)$. 시각적 감 별 능력의 교육 전 평균점수는 $6.8 \pm 3.6$ 점이었으며, 교육 후 $11.3 \pm 4.2$ 점으로, 통계적으로 유의한 차이가 있었다 $(\mathrm{t}=10.58, p<.001)$.

\section{3. 욕창 분류체계와 실금관련 피부염에 대한 시각적 감별 능력 영역별 분석}

연구대상자의 욕창 분류체계 및 실금관련 피부염에 대한 시각적 감별 능력의 영역별 변화를 비교한 분석 결과는 Figures 1, 2에 정리 하였다. 교육 전 욕창 1단계(20.3\%)와 미분류단계(5.7\%)와 혼동했던 창백성 홍반의 경우, 교육 전후 시각적 감별 정답률이 $58.3 \%$ 에서 $83.4 \%$ 로 상승하였다. 욕창 3 단계의 경우, 교육 전 욕창 4 단계(15.3\%), 욕창 2단계(11.8\%)로 잘못 분류하였으나, 교육 후에는 오히려 미분 류단계(14.9\%)와 가장 많은 혼동을 일으키는 것으로 나타났으며, 여

Table 2. Knowledge and Visual Discrimination Ability of Pressure Ulcer Classification and Incontinence Associated Dermatitis

\begin{tabular}{|c|c|c|c|c|c|}
\hline \multirow{2}{*}{ Total score } & Pre & Post & \multirow{2}{*}{ Range } & \multirow{2}{*}{ Paired t } & \multirow{2}{*}{$p$} \\
\hline & Mean $\pm S D$ & Mean $\pm S D$ & & & \\
\hline \multirow[t]{2}{*}{ Knowledge (Min-Max) } & $12.4 \pm 4.4$ & $14.9 \pm 3.3$ & \multirow[t]{2}{*}{$0-19$} & \multirow[t]{2}{*}{4.67} & \multirow[t]{2}{*}{$<.001$} \\
\hline & 0-18 & 0-18 & & & \\
\hline \multirow[t]{2}{*}{ Visual Discrimination ability (Min-Max) } & $6.8 \pm 3.6$ & $11.3 \pm 4.2$ & \multirow[t]{2}{*}{$0-21$} & \multirow[t]{2}{*}{10.58} & \multirow[t]{2}{*}{$<.001$} \\
\hline & 0-15 & $0-18$ & & & \\
\hline
\end{tabular}




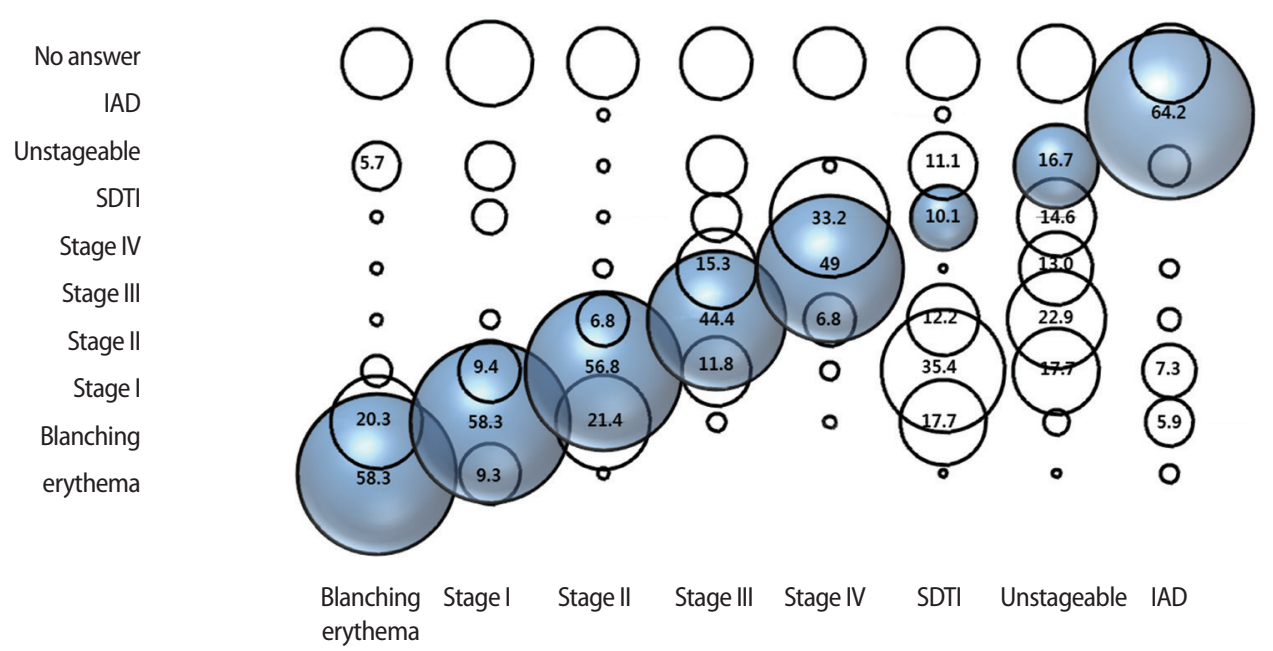

Figure 1. Pre-test answer rate on visual discrimination tool by the nurses $(\mathrm{N}=96) . \mathrm{IAD}=$ Incontinence-associated dermatitis; $S \mathrm{STI}=$ Suspected deep tissue injury.

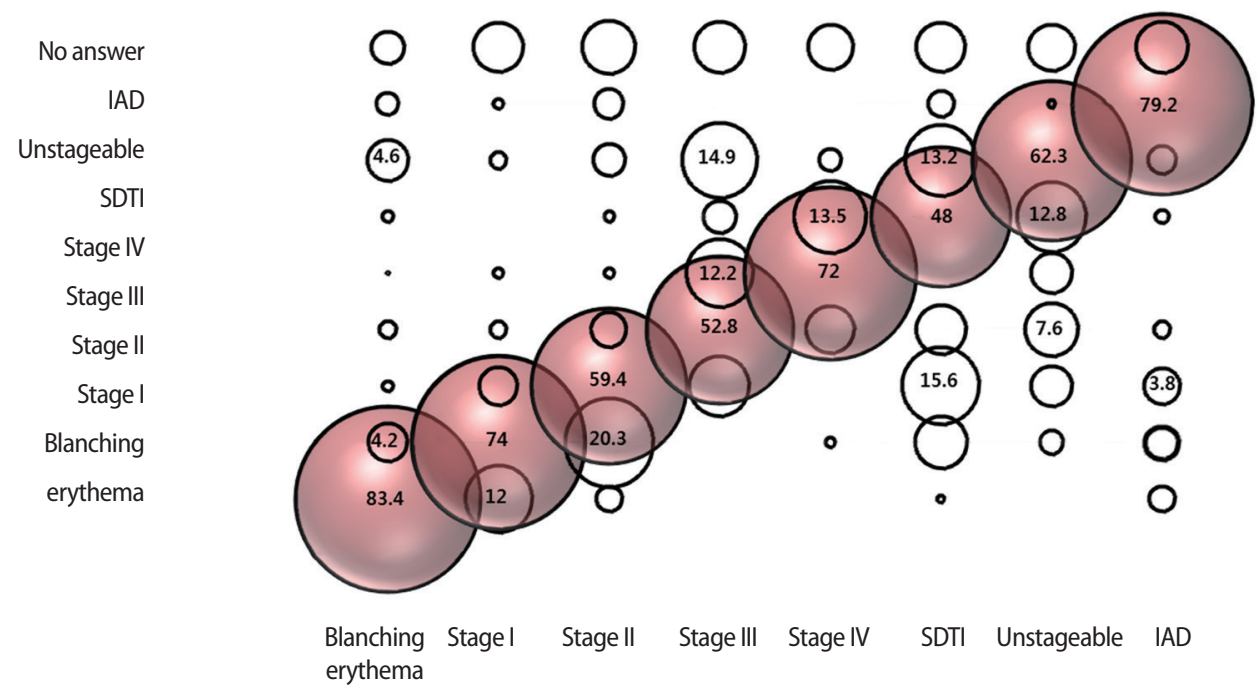

Figure 2. Post-test answer rate on visual discrimination tool by the nurses ( $N=96)$. IAD $=$ Incontinence-associated dermatitis; $S D T I=$ Suspected deep tissue injury.

전히 욕창 4단계(12.2\%)로 잘못 진단하는 것으로 나타났다.

교육 전 가장 낮은 정답률을 보인 심부조직손상 의심단계(10.1\%) 는 대부분의 경우, 욕창 2 단계(35.4\%)와 욕창 1단계(17.7\%)로 오인하 여 진단하였으며, 교육 후에도 욕창 2단계(15.6\%), 미분류단계(13.2\%) 와 혼동하는 결과를 보여 다른 욕창 분류체계에 비하여 정확한 진 단에 어려움이 있는 것으로 나타났다. 미분류단계의 경우 교육 전 $16.7 \%$ 의 낮은 정답률을 보였으며, 이를 욕창 3 단계 $(22.9 \%)$, 욕창 2 단 계(17.7\%), 미분류단계(16.7\%), 심부조직손상 의심단계(14.6\%) 순으로 잘못된 분류를 하는 결과를 나타냈으며, 교육 후에는 $62.3 \%$ 로 정답 률은 상승되었지만, 심부조직손상 의심단계(12.8\%)와 욕창 3단계 (7.6\%)와 혼동을 일으키는 것으로 확인되었다.
실금관련 피부염의 경우, 교육 전 욕창 2단계(7.3\%)와 혼동을 일 으키는 것으로 나타났으나, 교육 후에는 욕창 2 단계(3.8\%)와의 혼동 이 감소되는 결과를 보였다.

\section{논 의}

본 연구는 병원간호사의 욕창 사정에 관한 이론적 지식이 실제 임상현장에서 수행되고 있는 욕창 사정 실무적 기술에 얼마나 반 영되고 있는지를 간접적으로 보여주고 있다고 말할 수 있다. 기존의 욕창 간호에 대한 연구 결과에서 욕창 사정에 대한 지식은 매우 낮 은 결과를 보였다고 보고하였지만(Richbourg, Smith, \& Dunzweiler, 
2011) 평가를 위해 사용된 도구가 2007년 이후 새롭게 추가된 욕창 분류체계의 지식상태를 반영하고 있지 않다는 점을 고려해 볼 때, 현재 임상 실무에 반영함에 있어 어려움이 있다.

본 연구에서는 새롭게 추가된 욕창 분류체계인 심부조직손상 의 심단계와미분류단계를 포함하여 지식 수준을 측정하였다. 연구결 과 교육 전 지식수준이 중간 정도에서 다소 상승하는 결과를 나타 냈지만 높은 지식상태를 나타내지 못하여, 기존의 Lee 등이 시행한 연구와 비슷한 결과를 보였다(Lee et al., 2013; Kim \& Chung, 2013).

창백성 홍반과 욕창 1 단계인 비창백성 홍반을 구별하는 감별 능 력은 초기 욕창 예방에 중요한 예측요인으로 매우 중요하게 알려져 있다. 본 연구에서는 교육 전에는 창백성 홍반에 대한 지식 정도가 낮았던 데에 반하여, 교육 후 지식 정답률이 상승되었을 뿐 아니라 시각적 감별 능력 점수 또한 교육 전에 비교하여 통계적으로 유의 한 차이가 있음을 보였다. 이는 교육 후에도 욕창 1단계인 비창백성 홍반을 구별하는데 여전히 어려움이 있었다고 보고한 기존 연구결 과(Beeckman et al., 2008)와는 달리 본 연구에서는 교육을 통해 시각 적 감별 능력이 향상되었음을 나타냈다. 이는 본 연구에서 사용한 시각적 감별 능력 도구가 기존의 연구에서 사용된 단순한 사진 자 료와는 다르게 대상자의 추가적인 위험요인을 확인할 수 있도록 의 학적 진단, 환자 기동성, 배변상태, 경장영양주입여부, 상처보유기간 등을 표시하여 초기 정보 제공 시 감별진단을 용이하도록 하였을 뿐 아니라, 교육프로그램을 통하여 욕창 발생기전을 설명하고, 손 가락을 이용한 반동성 출혈검사 등을 통하여 창백성 홍반을 설명 하는 반동성 충혈의 변화양상을 시간적 순서에 따라 제시해 줌으 로써 차별화를 둔 점이 기여하였다고 생각된다.

그러나, 욕창 3 단계를 나타내는 일부 사진의 감별 능력점수는 오 히려 교육 전에 비해 교육 후 낮아지는 양상을 보였다. 이는 욕창 사 정에 필요한 시각적 감별 능력에 있어서 교육 후에도 피부조직에 대 한 부족한 해부학적 지식이 정확한 사정을 수행하는데 부정적으로 영향을 미쳤음을 간접적으로 시사한다고 해석할 수 있다.

심부조직손상 의심단계와 미분류단계의 경우에는 시각적 감별 능력은 교육 전 매우 낮은 수준으로 나타났지만, 교육 후에 매우 정 답률이 높아져 교육프로그램에 효과가 있었음을 보였다. 하지만, 욕 창 3 단계의 경우는 교육 후에도 욕창 4 단계나 미분류욕창으로 잘 못 판단하는 경우가 적지 않게 보고되고, 심부조직손상 의심단계도 미분류욕창이나 욕창 2 단계로 잘못 진단하는 경우가 있어 기존의 연구결과와 비슷한 결과를 나타냈다(Lee et al., 2013; Kim \& Chung, 2013). 욕창 2 단계의 경우, 교육 전의 시각적 감별 능력 정답률이 $56.8 \%$ 에서 교육 후 $59.4 \%$ 로 변화가 거의 없어, Kim과 Chung (2013)의 연구결과와 유사하였다. 이는 도구에 이용된 사진을 통하여 색의
변화와 수포 형성 등을 구별하는데 있어서 시각적인 측면만을 고려 하여 측정하였다는 제한이 있어, 대상자의 진단과, 기동성, 욕창 위 치 등의 추가적인 사정내용이 포함되어 있는 자료라 할지라도 정확 한 사정을 시행하는 데 한계가 있었음으로 해석할수 있다.

또한 심부조직손상 의심단계는 국제욕창자문위원단이 이론적 정의에서 기술한 전형적인 형태와 달리 여러 가지 욕창 단계가 혼재 되어 있는 경우가 빈번하기 때문에 병원간호사가 혼동을 초래했을 것으로 여겨진다. 교육 후에도 여전히 혈액이 차 있는 수포의 경우 에 있어서는 욕창 2 단계와 여전히 혼돈을 일으키고 있으며, 실제 임 상현장에서 적절한 치료에도 불구하고, 미분류단계로 진행되었다 가, 욕창 3,4 단계로 진행되는 경우가 흔하며, 비창백성 홍반이나 창 백성 홍반, 욕창 2단계, 미분류단계와 혼재되어 나타나는 경우가 있 다고 보고한 선행 연구결과에서 동일하게 해석되어 질 수 있다. 따 라서 이를 환자의 임상적 정보가 기재되어 있다하더라도, 욕창 분 류를 시각적으로만 감별하는 데 무리가 있었을 것으로 여겨진다 (Lee, Kim, \& Lee, 2011; Lee et al., 2013). 특히 일부 환자에 있어서는 적 절한 체위변경과 대상자의 상태가 호전되면서 2 단계로 진행되는 경 우 또한 임상현장에서 보고되면서, 욕창 분류체계에서 정의한 내 용과 달리 일반적인 진행양상을 띄지 않는다는 점이 정확한 욕창 사정에 혼란을 초래하고 있다고 여겨진다. 이는 욕창 분류체계에 대한 관찰자간 신뢰도가 0.8 의 높은 신뢰도 수준을 보였지만, 타당 도 면에 있어서는 심부조직손상 의심단계의 경우 정의된 내용이 실 제 임상에서의 욕창 사정에 어려움이 있어 추가적인 연구의 필요성 을 제언한 기존의 연구를 뒷받침해준다고 말할 수 있다(Lee et al., 2013; Lee, Kim, \& Lee, 2011; Richbourg, Smith, \& Dunzweiler, 2011).

실금관련 피부염의 경우 시각적 감별 능력이 교육 후 매우 상승 되는 결과를 보여, 욕창 2 단계와 실금관련 피부염을 구별하는데 어 려움이 있었다고 보고한 연구들과 차이를 보였다(Beeckman et al., 2008; Defloor \& Schoonhoven, 2004; Defloor, Schoonhoven, Katrien, Weststrate, \& Myny, 2006). 이는 실금관련 피부염에 대한 이론적 지 식에 대한 사정이 없이 사진만을 이용하여 평가한 국외 연구와 달 리 본 연구에서는 사진을 이용한 시각적 진단 이외에 실금관련 피 부염 발생이나 치료 예후에 영향을 미칠 수 있는 위험 요인을 구별 할 수 있는 의학적 진단, 환자 기동성, 배변상태, 경관유동식 주입 유무, 상처보유기간 등 환자의 임상적 정보가 포함한 도구를 사용 하였기 때문인 것으로 여겨지며, 교육프로그램의 효과로 교육 후 점 수가 상승되어 기존의 연구에서 보다 높은 점수를 나타냈다고 생각 된다(Chianca, Rezenda, Borges, Nogueira, \& Caliri, 2010). 하지만 본 연구를 통하여 교육 후에도 여전히 혼돈을 일으키는 욕창 분류체 계의 정확한 진단을 위해 현재 시행되고 있는 교육프로그램의 전 
환이 요구됨을 알 수 있다. 따라서 기존 학습형태와 차별화하여 실 제 임상 현장에서 임상전문가와 상호작용할 수 있는 실무 중심의 학습을 겸한 다양한 교육프로그램의 구성이 필요할 것이다.

\section{결론 및 제언}

본 연구결과는 욕창 분류체계 교육프로그램을 받은 후 욕창 분 류체계 및 실금관련 피부염에 대한 이론적 지식과 시각적 감별 능력 이 상승하며 통계적으로 유의하게 차이가 있음을 보여주었다. 욕창 을 예방하는데 중요한 창백성 홍반과 욕창 1단계로 분류되는 비창 백성 홍반에 대한 시각적 감별 능력 정답률에서도 교육 후 증가하는 결과를 보여주었다. 하지만, 욕창 2단계와 욕창 3 단계, 심부조직손상 의심단계는 시각적 감별 능력이 교육 후에도 여전히 낮은 수준의 정 답률을 보이고 있어, 임상 실무에서의 욕창 3 단계와 심부조직손상 의심 단계를 감별하여 진단하는데 혼동을 일으킴을 나타냄으로써 다른 욕창 분류 단계로 잘못 진단되어 질 수 있음을 보여주었다.

이러한 연구결과를 고려해 볼 때, 부적절한 욕창 분류단계로 사 정됨으로써 오는 임상에서의 욕창 예방과 치료의 오류를 막기 위 해서 이론적 지식의 기반이 올바르게 임상실무에 적용되기 위한 교 육 프로그램이 필요하다. 이를 위해 현재 간호사의 계속교육프로그 램으로 대부분을 차지하고 있는 전형적인 강의 위주의 전달식 교육 프로그램에서 욕창 호발 부위의 해부학적 지식과 사례 중심별 교 육내용과 구성요소를 포함한 실무 측면이 강조된 교육프로그램이 필요하다고 말할 수 있다. 따라서 욕창 사정의 이론적 지식과 실무 에서의 시각적 감별 능력을 향상시키기 위한 다양한 방법의 교육프 로그램의 효과를 파악할 수 있는 연구를 제안한다. 또한 일회성 교 육의 사전 사후 결과를 비교하였으므로 장기간의 시간이 지난 후 교육효과를 파악할 수 있는 후속 연구가 필요하다.

\section{REFERENCES}

Altun, I., \& Zencirci, D. A. (2011). Knowledge and management of pressure ulcers: Impact of lecture-based interactive workshops on training of nurses. Advances in Skin \& Wound Care, 25(6), 262-266. http://dx.doi.org/10.1097/01.ASW.0000 398664.7 4153.ce

Aydin, A. K., \& Karadag, A. (2010). Assessment of nurses' knowledge and practice in prevention and management of deep tissue injury and stage I pressure ulcer. Journal of Wound, Ostomy, and Continence Nursing, 37(5), 487-494.
Baumgarten, M., Margolis, D. J., Localio, A. R., Kagan, S. H., Lowe, R. A., Kinosian, B., et al. (2006). Pressure ulcers among elderly patients early in the hospital stay. The Journals of Gerontology. Series A, Biological Sciences \& Medical Sciences, 61(7), 749-754. http://dx.doi.org/10.1093/gerona/61.7.749

Beeckman, D., Schoonhoven, L., Boucqué, H., Maele, G. V., \& Defloor, T. (2008). Pressure ulcer: E-learning to improve classification by nurses and nursing students. Journal of Clinical Nursing, 17(13), 1697-1707. http://dx.doi.org/10.1111/j. 1365-2702.2007.02200.x

Chianca, T. C., Rezende, J. F., Borges, E. L., Nogueira, V. L., \& Caliri, M. H. (2010). Pressure ulcer knowledge among nurses in a Brazilian university hospital. Ostomy Wound Management, 56(10), 58-64.

Defloor, T., \& Schoonhoven, L. (2004). Inter-rater reliability of the EPUAP pressure ulcer classification system using photographs. Journal of Clinical Nursing, 13(8), 952-959. http://dx.doi.org/10.1111/j.1365-2702.2004.00974.x

Defloor, T., Schoonhoven, L., Katrien, V., Weststrate, J., \& Myny, D. (2006). Reliability of the European Pressure Ulcer Advisory Panel classification system. Journal of Advanced Nursing, 54(2), 189-198. http://dx.doi.org/ 10.1111/j.1365-2648. 2006.03801.x

Gray, M., Bohacek, L., Weir, D., \& Zdanuk, J. (2007). Moisture vs pressure: making sense out of perineal wounds. Journal of Wound Ostomy Continence Nursing, 34, 134-142.

Gray, M. (2010). Optimal management of incontinence-associated dermatitis in the elderly. American Journal of Clinical Dermatology, 11(3), 201-210. http://dx. doi.org/10.2165/11311010-000000000-00000

Hopkins, A., Dealey, C., Bale, S., Defloor, T., Worboys, F. (2006). Patient stories of living with a pressure ulcer. Journal of Advanced Nursing, 56(4), 345-353. http:// dx.doi.org/10.1111/j.1365-2648.2006.04007.x

Kim, M. S., \& Chung, S. S. (2013). Empowerment of clinical nurses' knowledge of pressure ulcer staging by phtographic-centered education. The Proceedings of the Congress Aisa Pacific Enterostomal Therapy Nurses Association, Seoul, Korea

Kim, S. S. (2003). Evaluating the predictive validity for the new pressure sores risk assessment scale, Unpublished master's thesis. Chung-Ang University, Seoul.

Lee, E. J., \& Yang, S. O. (2011). Clinical knowledge and actual performance of pressure ulcer care by hospital nurses. Journal of Korean Clinical Nursing Research, 17(2), 251-261.

Lee, Y. J., Kim, J. Y., \& Lee, T. W. (2011). Inter-rater reliability of the pressure ulcer classification system. Journal of Korean Wound Management Society, 7(2), 75-80.

Lee, Y. J., Park, S. M., Kim, J. Y., Kim, C. G., \& Cha, S. K. (2013). Clinical nurses' knowledge and visual differentiation ability in pressure ulcer classification system and incontinence-associated dermatitis. Journal of Korean Academy of Nursing, 43(4), 526-535, http://dx.doi.org/10.4040/jkan.2013.43.4.526

Richbourg, L., Smith, J., \& Dunzweiler, S. (2011). Suspected deep tissue injury evaluated by North Carolina WOC nurses: A descriptive study. Journal of Wound, Ostomy and Continence Nursing, 38(6), 655-660. http://dx.doi.org/10.1097/ WON.0b013e31823429e7

Sinclair, L., Berwiczonek, H., Thurston, N., Butler, S., Bulloch, G., Ellery, C., et al. (2004). Evaluation of an evidence-based education program for pressure ulcer prevention. Journal of Wound Ostomy \& Continence Nursing, 31(1), 43-50. 